\title{
Estatuto da \\ Academia Paulista de Medicina Veterinária (APAMVET)
}

\section{PREFÁCIO}

Desde muito, um grupo de médicos veterinários de São Paulo sonhava com a Academia Paulista de Medicina Veterinária, a exemplo da Academia Brasileira de Medicina Veterinária e daquelas já existentes em outros Estados da União, para reverenciar aqueles ilustres colegas que nos antecederam e, saudosamente, sobrevivem em nossas memórias e que, por sua atitude e dedicação, nos legaram a significativa evolução e desenvolvimento das Ciências Veterinárias: é certo e oportuno atribuir-lhes os avanços e a respeitabilidade de nossa Profissão. Há muito a eles devíamos uma homenagem. Desse modo, nada mais oportuno e representativo seria designá-los e nomeá-los PATRONOS DAS CÁTEDRAS da APAMVET - ACADEMIA PAULISTA DE MEDICINA VETERINÁRIA que serão ocupadas pelos 50 (cinqüenta) Acadêmicos dessa novel instituição cultural, dos quais dezesseis (16) foram nomeados recentemente.

Entretanto, para que o sonho se tornasse realidade, havia a necessidade de aglutinação de idéias ao redor de propostas renovadoras e iniciativas lideradas por ativo núcleo profissional de escol, convergindo os esforços ao redor desse centro com estrutura capacitada, que permitisse levar a cabo a criação e implantação dos ideais de formação da Academia Paulista de Medicina Veterinária.

Em passado remoto - bem como, de forma mais ativa e consistente, em passado recente -, surgiram alguns focos de ensaios para consecução desses ideais. Tal fato originou, em locais envolvidos, a necessidade da criação de uma ACADEMIA PROFISSIONAL, como foram os casos da Sociedade Paulista de Medicina Veterinária (SPMV) e da Faculdade de Medicina Veterinária e Zootecnia (FMVZ), na Universidade de São Paulo (USP). Nesses centros de ensino e de cultura profissional, locais de maior envolvimento com a história da Medicina Veterinária em São Paulo, desenvolveram-se significativos movimentos profissionais para o engrandecimento e reconhecimento da profissão dos médicos veterinários em nosso Estado. Porém, para que fosse alcançado o desiderato proposto, havia necessidade da participação de um órgão centralizador que, além de estimular, coordenasse os interesses, dando uma diretriz aos objetivos colimados. Por tais razões, numa das reuniões plenárias do CRMV-SP, precisamente a 27ª , realizada em 27 de novembro de 1997, o Professor Doutor Flávio Prada apresentou o pioneiro projeto de criação da, então denominada, Academia Paulista de Ciências Veterinárias, que aplaudido por todos os participantes foi aprovado, por unanimidade.

Contudo, apesar de contar com o entusiasmo dos colegas participantes do evento, na época, a criação e implantação da Academia Paulista de Medicina Veterinária permaneceu em estado de latência, procurando o necessário fortalecimento de suas bases. Nesses momentos, não tão distantes no tempo, embora não estivesse 
a Academia implantada de fato, a motivação de sua criação crescia, tanto nas conversas informais de colegas, como também nos encontros e reuniões cientificas. Os resultados da discussão de tão emocionante motivação, verdadeira conversação daqueles colegas entusiastas do projeto e que ansiavam participar ativamente do nascimento da Academia Paulista de Medicina Veterinária, concretizaram-se, finalmente, em 9 de setembro de 2004, na cidade de Santos - São Paulo. O fato ocorreu durante a realização do $6^{\mathbf{0}}$ Congresso Paulista de Medicina Veterinário, 59 ${ }^{\text {a }}$ Conferência Anual da Sociedade Paulista de Medicina Veterinária e $6^{\circ}$ Encontro de Entidades de Classe de Profissionais da Medicina Veterinária, tradicionais eventos sóciocientíficos promovidos pela Sociedade Paulista de Medicina Veterinária (SPMV) e pelo Conselho Regional de Medicina Veterinária em São Paulo (CRMV-SP). Assim, foi fundada, por ação direta de seu Interventor Judicial - Professor Doutor Flávio Prada, a Academia Paulista de Medicina Veterinária, em Santos, SP.

Na ocasião, decidiu-se que o CRMV-SP acolheria a novel entidade em suas dependências e iniciaria seus trabalhos pela ação de uma Comissão de Instalação da Academia Paulista de Medicina Veterinária (Resolução CRMV-SP n 1.186, de 10 de janeiro de 2005), que coordenaria e daria início aos procedimentos necessários para a implantação legal e definitiva da APAMVET.

Os trabalhos desta Comissão, para instalação da APAMVET, contaram com a ativa participação do Professor Doutor Eduardo Harry Birgel (CRMV-SP n 00018), como Presidente, e da Doutora Arani Nanci Bomfim Mariana (CRMV-SP n 1445) como Coordenadora dos trabalhos. Teve ainda como participantes os acadêmicos da Academia Brasileira de Medicina Veterinária (ABMV), Professora Doutora Clotilde de Lourdes Branco Germiniani (CRMV-PR nº 00110) e o Professor Doutor Sérgio Coube Bogado (CRMV-RJ n 2715), assessorado pela sempre, prestativa e eficiente colaboração do Advogado Pyrro Massela. Esse laborioso trabalho administrativo resultou na elaboração do Estatuto da Academia Paulista de Medicina Veterinária e, enfim, estava a Medicina Veterinária Paulista pronta para, em sua história, iniciar as atividades da Academia Paulista de Medicina Veterinária.

Na oportunidade, almejou-se que a Academia se transformasse no local ideal para reuniões e confraternizações e representasse o fermento científico do qual os jovens veterinários pudessem fazer uso, à luz das realizações e propostas dos Acadêmicos, e neles espelharem-se colaborando com ações positivas para um mundo melhor. Almejou-se, também, que nesse local a convivência entre os pares fosse sempre pacífica, observando-se a excelência da formação e atuação dos profissionais da Medicina Veterinária.

Na Reunião Plenária de Implantação da Academia Paulista de Medicina Veterinária, realizada em 17 de novembro de 2005, foi empossada a Comissão Especial de Gestão, composta pelos ilustres colegas Eduardo Harry Birgel (Presidente), Nanci Arani Bomfim Mariana (Coordenadora), Antonio Fernandes Filho, Renato Campanarut Barnabé, Hélio Ladislau Stempniewisky, Hélio Emerson Belluomini, José Cezar Panetta, Raphael Valentino Richetti, Vicente do Amaral e Olympio Geraldo Gomes -, instituída como determinava a Resolução nํㅜ 1.186 do CRMV-SP e Artigo 5ํ do Estatuto da APAMVET, que assumiram a incumbência de designar em duas etapas os primeiros 26 (vinte e seis) Patronos das Cátedras da Academia e seus respectivos acadêmicos. 


\section{Estatuto da \\ Academia Paulista de Medicina Veterinária (APAMVET)}

\section{Título I}

\section{Da Denominação, Sede, Duração e Objetivos}

Art. 1ำ - A Academia Paulista de Medicina Veterinária (APAMVET) - fundada em 9 de setembro de 2004, sediada na rua São Samuel n 191 , São Paulo, SP, CEP. 04120-030, com foro na cidade de São Paulo e duração ilimitada, é uma entidade civil de direito privado, sem fins lucrativos, tendo por objetivos:

I - Cultivar a observância da Deontologia, bem como o estudo da História e da Ciência Médico-Veterinárias;

II - Promover o intercâmbio técnicocientífico, cultural e social entre as entidades congêneres e instituições públicas e privadas com atividades ligadas à Medicina Veterinária;

III - Contribuir para o desenvolvimento, o congraçamento e o progresso geral da Medicina Veterinária;

IV - Promover a profissão médico-veterinária perante a sociedade;

V - Contribuir para o aprimoramento do ensino médico-veterinário.

Art. $2^{\circ}$ - Para cumprir suas finalidades, compete à Academia:

I - Instituir prêmios a trabalhos publicados e pesquisas realizadas de interesse significativo para a Medicina Veterinária e de grande valor para as Ciências Veterinárias;

II - Promover reuniões de estudos de interesse da profissão;

III - Instituir e conferir títulos honoríficos, comendas e outras honrarias às pessoas que, por suas atividades e desempenho, contribuíram para o progresso da Ciência
Médico-Veterinária e da cultura em geral;

IV - Instituir galerias dos membros acadêmicos fundadores da Academia, dos patronos, dos ex-presidentes e dos seus membros honorários, como forma de homenageá-los perenemente;

V - Estimular ou promover a publicação de trabalhos e pesquisas de temas fundamentais da cultura e história da Medicina Veterinária;

VI - Instituir biblioteca e museu.

Art. 3ำ - Os símbolos da APAMVET são: a bandeira, o brasão, a medalha, o fardão e o hino, cujos instituição e uso serão objeto do regimento interno.

\section{Título II}

\section{Das Cadeiras e dos Patronos}

Art. 4ำ - Haverá 50 (cinqüenta) cadeiras, criadas para homologar renomados profissionais, seus respectivos patronos e membros titulares que por ela passarem.

Art. 5-AAPAMVET compõe-se de membros acadêmicos qualificados nas seguintes categorias:

I - Membros Titulares;

II - Membros Eméritos;

III - Membros Honorários;

IV - Membros Correspondentes.

§ 1ํ-Membros Titulares são os Médicos Veterinários brasileiros integrantes das 50 (cinqüenta) cadeiras da APAMVET.

$\S 2^{\circ}$ - Membros Eméritos são acadêmicos com, no mínimo, 15 (quinze) anos de APAMVET e serviços relevantes 
prestados à Medicina Veterinária, aos quais é facultado enquadrarem-se em tal categoria, mantidos seus direitos e deveres.

§ 3- Membros Honorários são médicos veterinários e ou personalidades notórias, propostos e eleitos por escrutínio, em sessão específica da APAMVET, em virtude de possuírem títulos ou trabalhos de reconhecido valor técnico-científico ou terem prestado serviços relevantes ao País, à Medicina Veterinária ou à sociedade.

§ 4 - Membros Correspondentes são médicos veterinários de reconhecido valor e probidade, não residentes no Estado de São Paulo, indicados pela Diretoria Executiva da APAMVET e aprovados, em escrutínio específico pelo Colegiado, visando ao intercâmbio profícuo com a APAMVET.

\section{Título III}

\section{Da Admissão e Demissão de Acadêmicos}

Art. 6ํ- - O Presidente da APAMVET abrirá, pelo prazo mínimo de 2 (dois) meses, inscrição para preenchimento de vaga de Membro Titular, na sessão subseqüente à sua ocorrência.

$\$ 1^{\circ}-\mathrm{O}$ julgamento dos candidatos regularmente inscritos será feito por Comissão Especial, constituída por 7 (sete) Membros Acadêmicos Titulares, designados pela Diretoria Executiva da APAMVET.

§ 2ำ A qualificação dos candidatos consistirá no julgamento do seu memorial, cabendo à Comissão Especial proferir parecer circunstanciado e conclusivo sobre a classificação dos candidatos, submetendo-o à Assembléia Geral da APAMVET.

Art. $7^{\circ}-\mathrm{O}$ candidato indicado para Membro Titular tomará posse dentro de 60 (sessenta) dias, contados a partir do momento em que tomar ciência de sua indicação, devendo antes recolher a Tesouraria da APAMVET os valores da jóia e outras contribuições regimentais.

Art. $8^{\circ}-$ A posse dos Acadêmicos será realizada em sessão solene da APAMVET, cabendo ao seu Presidente proceder à entrega dos respectivos diplomas e insígnias acadêmicas aos empossados.

Art. 9ำ - O Membro Titular que completar 15 (quinze) anos de vida acadêmica, fará jus à categoria de Membro Emérito, sendo-lhe garantidos todos os direitos e prerrogativas anteriormente adquiridos.

Art. 10 - Os Membros Honorários serão indicados por Colegiado composto por Membros Acadêmicos Titulares e aprovados pela Assembléia Geral, sendo o diploma e a medalha entregues em sessão solene, sob inteira responsabilidade da APAMVET.

Art. 11 - O Membro Correspondente terá seu título registrado em livro próprio, mantido pela Secretaria e destinado única e exclusivamente para essa finalidade.

Art. 12 - O número de Membros Eméritos, Honorários e Correspondentes, respectivamente, não poderá ultrapassar o de Membros Titulares da APAMVET.

Art. 13 - Deixarão de fazer parte da APAMVET os membros que solicitarem formalmente sua desvinculação da Academia e os que forem demitidos por infração de dispositivos legal, estatutário ou regimental.

Art. 14 - As desvinculações e, principalmente, as demissões de qualquer Membro Acadêmico somente serão efetivadas pela Assembléia Geral, após sindicância que tenha oferecido total oportunidade de defesa, com esclarecimento pleno dos motivos determinantes da penalidade.

Parágrafo único - compete à DiretoriaExecutiva instaurar sindicância para apurar denúncia escrita e identificada contra membro da APAMVET. 
Art. 15 - É irrecorrível, no âmbito da APAMVET, a desvinculação ou demissão de membro da ACADEMIA baseadas na condenação em sentença definitiva por crime infamante e prática de grave atentado à Deontologia e à Ética Médico-Veterinária.

\section{Título IV}

\section{Dos Direitos e Deveres dos Acadêmicos}

Art. 16 - São direitos dos Acadêmicos Titulares ou Eméritos:

I - participar das reuniões da APAMVET;

II - votar e ser votado para cargos eletivos, usando, quando houver impossibilidade de participação nos pleitos, o voto por correspondência ou procuração;

III - propor medidas julgadas convenientes ao bom funcionamento da APAMVET;

IV - representar contra atos da Administração ou dos Acadêmicos, prejudiciais aos interesses da APAMVET;

V - receber publicações da APAMVET;

VI - publicar obras sob o patrocínio da APAMVET, mediante entendimento prévio com a Administração.

Parágrafo único - São extensivos, aos Membros Honorários e Correspondentes as disposições constantes do inciso V.

Art. 17 - São deveres dos Membros Titulares e Eméritos:

I - respeitar e fazer respeitar o Estatuto da APAMVET;

II - zelar pelo progresso, decoro e renome da APAMVET;

III - comparecer às reuniões para as quais for convocado, aceitando exercer cargos, participar de comissões ou receber incumbência, salvo motivo justificado;

IV - atender ao pagamento das contribuições estabelecidas pela Diretoria e de outros compromissos financeiros ajustados.

Parágrafo único - Os Membros Honorários e Correspondentes estão isentos dos pagamentos das contribuições mencionadas no inciso IV.

\section{Título $\mathbf{V}$ \\ Das Receitas e Bens Patrimoniais}

Art. 18 - A receita da APAMVET será constituída dos rendimentos, direitos transferidos e bens que possua, como doações recebidas e contribuições recolhidas pelos Acadêmicos.

Parágrafo único - Participam também da receita auxílios, legados e recursos advindos do recebimento de projetos e eventos contratados.

Art. 19 - O pagamento de despesas será efetuado mediante emissão de cheque assinado pelo Presidente, juntamente do Tesoureiro.

Art. 20 - Com o orçamento serão apresentados, anualmente, os dados das rubricas, para apreciação em Plenário, devendo a aprovação ser por maioria absoluta de votos.

Parágrafo único - Os recursos da APAMVET serão aplicados na manutenção dos seus objetivos estatutários.

Art. 21 - O patrimônio da APAMVET será constituído de bens móveis, imóveis e direitos que lhe tenham sido destinados, bem como dos adquiridos.

Art. 22 - Não é permitido alienar, gravar ou onerar, sob qualquer forma, os bens móveis, imóveis ou direitos da APAMVET, a não ser para permutar ou aquisição de bens similares de igual ou maior valor, com aprovação da Assembléia Geral.

\section{Título VI}

\section{Da Organização e Funcionamento}

Art. 23 - A Administração da APAMVET será constituída por:

$$
\begin{gathered}
\text { I - Assembléia Geral; } \\
\text { II - Diretoria-Executiva; } \\
\text { III - Conselho Fiscal. }
\end{gathered}
$$

Art. 24 - À Assembléia Geral, órgão soberano de deliberação superior da APAMVET, constituído 
por Membros Titulares e Membros Eméritos, compete:

$$
\begin{aligned}
\text { I - } & \text { eleger e empossar os membros da } \\
& \text { Diretoria-Executiva e do Conselho } \\
& \text { Fiscal; } \\
\text { II - } & \text { destituir os membros da Diretoria- } \\
& \text { Executiva e do Conselho Fiscal; } \\
\text { III - } & \text { analisar e votar, anualmente, o } \\
& \text { orçamento e prestação de contas da } \\
& \text { Diretoria-Executiva; } \\
\text { IV - } & \text { propor planos de trabalho de interesse } \\
& \text { da APAMVET; } \\
\text { V - } & \text { resolver assuntos de natureza social, } \\
& \text { submetidos ao seu julgamento; } \\
\text { VI - } & \text { alterar o Estatuto da APAMVET. }
\end{aligned}
$$

\section{Título VII}

\section{Da Diretoria-Executiva}

Art. 25 - A APAMVET é administrada pela Diretoria Executiva, eleita por três anos pelos seus pares e constituída por:

$$
\begin{aligned}
& \text { I - Presidente; } \\
& \text { II - Vice-Presidente; } \\
& \text { III - Primeiro Secretário; } \\
& \text { IV - Segundo Secretário; } \\
& \text { V - Primeiro Tesoureiro; } \\
& \text { VI - Segundo Tesoureiro. }
\end{aligned}
$$

Art. 26 - Não cabe qualquer tipo de remuneração aos membros da Diretoria-Executiva.

Art. 27 - A APAMVET será representada em juízo ou em suas relações com terceiros pelo seu Presidente, ou seu Representante legal.

Art. 28 - Compete à Diretoria-Executiva cumprir e fazer cumprir o Estatuto, o Regimento Interno, as resoluções baixadas pelo Presidente, bem como as decisões aprovadas pela Assembléia Geral e todos os atos pertinentes à administração da APAMVET.

Art. 29- Ao Presidente da APAMVET compete:

I - cumprir e fazer cumprir o presente Estatuto;
II - representar a APAMVET em juízo e fora dele;

III - superintender e coordenar as atividades da AMPAVET;

IV - convocar e presidir sessões, reuniões, assembléias e outros eventos;

V - assinar expediente e, juntamente com o Secretário, diplomas e certificados;

VI - abrir e movimentar contas bancárias em nome da APAMVET, juntamente com o Tesoureiro;

VII - apresentar o Relatório Anual das atividades acadêmicas;

VIII - submeter à Assembléia Geral, até março de cada ano, o balanço contábil do exercício anterior;

IX - submeter à Diretoria-Executiva a proposta orçamentária do correspondente exercício financeiro;

X - receber subvenções, auxílios, doações e outros valores, dando quitação;

XI - autorizar a Tesouraria e efetuar pagamentos de despesas.

Art. 30 - Ao Vice-Presidente compete auxiliar o Presidente e substituí-lo em suas faltas e impedimentos.

Art. 31 - Ao Primeiro Secretário compete:

I - substituir o Presidente, quando o VicePresidente faltar ou estiver impedido;

II - lavrar as atas de reuniões da DiretoriaExecutiva e da Assembléia Geral;

III - executar as atividades técnicas e administrativas determinadas pela Diretoria-Executiva, conforme instruções do Regimento Interno e manter sob sua responsabilidade toda documentação da APAMVET;

IV - manter, organizar e supervisionar os serviços da Secretaria.

Art. 32 - Ao Segundo Secretário compete:

I - auxiliar o Primeiro Secretário e substituílo em suas faltas e impedimentos.

Art. 33 - Ao Primeiro Tesoureiro compete:

I - administrar o patrimônio da APAMVET; 
II - superintender os serviços da Tesouraria;

III - manter sob sua guarda bens, valores, títulos e contas;

IV - responsabilizar-se pela execução de planos de captação de recursos, aprovados pela Diretoria-Executiva;

V - providenciar a realização de cobranças.

VI - efetuar os pagamentos, autorizados pelo Presidente.

Art. 34 - Ao Segundo Tesoureiro compete:

I - auxiliar o Primeiro tesoureiro e substituílo em suas faltas e impedimentos.

\section{Título VIII \\ Do Conselho Fiscal}

Art. 35 - O Conselho Fiscal - composto por três membros e respectivos suplentes, que exercerão seus mandatos sem remuneração - tem por competência:

I - acompanhar e fiscalizar a execução da gestão financeira da APAMVET;

II - registrar em livro próprio atas de suas reuniões, bem como os pareceres por ele emitidos.

Parágrafo único - Os membros do Conselho Fiscal serão eleitos juntamente à Diretoria-Executiva, com mandato de três anos.

Art. 36 - Aos Conselheiros Fiscais Suplentes compete auxiliar os respectivos Conselheiros Fiscais Efetivos e substituí-los em suas faltas ou impedimentos.

Art. 37 - O Conselho Fiscal reunir-se-á ordinariamente duas vezes por ano: ao término do primeiro e do segundo semestres do ano e, extraordinariamente, por convocação da maioria dos seus membros efetivos ou por solicitação da Presidência da APAMVET.

Parágrafo único - Nas reuniões do Conselho Fiscal, os Conselheiros Fiscais Suplentes poderão usar da palavra, porém, o direito de voto é privativo do Conselheiro Fiscal que estiver exercendo efetivamente o cargo.

\section{Título IX}

\section{Da Eleição e Posse da Diretoria}

Art. 38 - As eleições para os cargos da DiretoriaExecutiva e do Conselho Fiscal serão realizadas trienalmente, em Assembléia Geral, mediante escrutínio secreto e por chapa registrada na Secretaria, até 30 (trinta) dias antes da realização da eleição.

$\S \mathbf{1}^{\mathbf{0}}$ - A Assembléia Geral Eleitoral só será instalada e funcionará com a metade mais um dos Membros Titulares da APAMVET. Em não havendo “quorum”, será marcado, dentro de 60 (sessenta) dias, nova reunião eleitoral.

$\S 2^{\mathbf{o}}-$ É permitido o voto por procuração ou por correspondência, em casos plenamente justificáveis.

$\S 3^{\circ}-\mathrm{O}$ direito de votar, em eleições para membros da Diretoria ou do Conselho Fiscal, é privativo dos Membros Titulares e Eméritos da APAMVET, quites com a tesouraria.

Art. 39 - Serão proclamados eleitos os candidatos constantes da chapa que, na apuração, alcançarem a maioria simples dos sufrágios.

Art. 40 - A posse dos componentes da Diretoria-Executiva e do Conselho Fiscal deverá ser efetuada em sessão solene da APAMVET, obedecendo a cerimonial apropriado.

Art. 41 - As vagas ocorridas no triênio de gestão da Diretoria-Executiva e do Conselho Fiscal eleitos serão preenchidas mediante eleição específica, desde que faltem mais de seis meses para o término do mandato. Caso contrário, o Presidente indicará Diretor e Conselheiro pro tempore, indicação que prevalecerá até a realização do próximo pleito e investidura dos eleitos.

\section{Título X \\ Disposições Gerais e Transitórias}

Art. 42 - Aprovado o presente Estatuto, a APAMVET organizará o seu Regimento Interno, que 
disciplina todas as atividades acadêmicas no que for julgado útil ao cumprimento dos objetivos da entidade.

Art. 43 - A vigência do presente Estatuto implicará na imediata realização de eleição para a Assembléia Geral e o Conselho Fiscal, nos moldes recomendados pelo instrumento legal.

Art. 44-AAPAMVET, como pessoa jurídica de direito privado, terá personalidade distinta de seus membros, os quais não responderão subsidiariamente pelas obrigações contraídas em seu nome por seus representantes.

Art. 45 - Até a aquisição da sede própria, a APAMVET funcionará em dependências cedidas pelo Conselho Regional de Medicina Veterinária do Estado de São Paulo (CRMV-SP), situado na Rua São Samuel n 191, Vila Mariana, CEP: 04120-030, São Paulo, SP.

Art. 46 - A indicação das primeiras 16 (dezesseis) cadeiras da APAMVET será feita por Comissão Especial composta por 9 (nove) membros, designados pela comissão instituída pela Resolução - CRMV-SP nº 1186/2005 de 10/01/2005.
Art. 47 - Os 16 (dezesseis) acadêmicos indicados providenciarão, em duas etapas, a seleção de outros 10 (dez) acadêmicos e patronos.

Art. 48 - Após a seleção de mais da metade do número de patronos e seus respectivos acadêmicos, será feita a eleição da Diretoria da APAMVET e o registro do estatuto, aplicando-se seus dispositivos para a indicação dos demais patronos e acadêmicos.

Art. 49 - Em caso de dissolução da APAMVET, que só poderá ser decidida em Assembléia Geral pelo voto de três quartos da totalidade de seus Membros Titulares e Eméritos, todos os seus bens serão entregues ao Conselho Regional de Medicina Veterinária do Estado de São Paulo (CRMV-SP), para serem aplicados em instituições de fins congêneres ou entidades filantrópicas.

Art. 50 - Os casos omissos e as dúvidas que surgirem na execução deste Estatuto serão dirimidos pela Diretoria-Executiva, ouvida a Assembléia Geral.

Art. 51 - O presente Estatuto entrará em vigor na data de sua aprovação pela Assembléia Geral.

Art. 52 - Revogam-se as disposições em contrário. 